\title{
GEOMETRICAL OPTIMIZATION OF MIXED CONVECTIVE FLOWS OVER TRIANGULAR ARRANGEMENT OF CYLINDERS
}

\footnotetext{
G. M. Barros ${ }^{\mathbf{a}}$,

M. dos S. Pereira ${ }^{a}$,

D. M. do Carmo ${ }^{b}$,

R. Cemin ${ }^{b}$,

L. A. Isoldi ${ }^{\mathrm{a}}$,

L. A. O. Rocha ${ }^{c}$,

and E. D. dos Santos ${ }^{\mathrm{a}}$

${ }^{a}$ Universidade Federal do Rio Grande

Programa de Pós-Graduação em Engenharia

Oceânica

Av. Itália, km 8, CEP. 96203-900, Rio Grande,

Rio Grande do Sul, Brasil

elizaldosantos@furg.br

${ }^{b}$ Universidade Federal do Rio Grande

Escola de Engenharia

Av. Itália, km 8, CEP. 96203-900, Rio Grande,

Rio Grande do Sul, Brasil

${ }^{c}$ Universidade Federal do Rio Grande do Sul

Departamento de Engenharia Mecânica

Rua Sarmento Leite, 425, CEP 90050-170,

Porto Alegre, Rio Grande do Sul, Brasil

Received: October 14, 2016

Revised: November 01, 2016

Accepted: November 14, 2016
}

\section{ABSTRACT}

The present study consists on the numerical evaluation of a triangular arrangement of circular cylinders submitted to transient, two-dimensional, incompressible, laminar and mixed convective flows. The geometrical evaluation is performed by means of Constructal Design. For all simulations it is considered Reynolds and Prandtl numbers of $\operatorname{Re}_{\mathrm{D}}=100$ and $\mathrm{Pr}=0.71$. Moreover, three different values of Richardson number are investigated: Ri $=0.1$ (which represents flows dominated by forced convective), 1.0 (which represents an equilibrium between forced and natural driven forces) and 10.0 (which represents flows with dominance of natural convective). The conservation equations of mass, momentum and energy are solved with the use of Finite Volume Method (FVM). The buoyancy forces are tackled with the Boussinesq approximation. The area occupied by the triangular arrangement of cylinders is a geometric constraint of the problem and the cylinders have the same diameter. The main purpose is to evaluate the effect of Richardson number over the drag coefficient $\left(C_{D}\right)$ and Nusselt number $\left(\mathrm{Nu}_{\mathrm{D}}\right)$ between the cylinders and the surrounding flow, as well as, over the optimal ratio $S_{\mathrm{T}} / \mathrm{D}$ (ratio between transversal pitch and the cylinder) for two different values of the ratio $S_{L} / D=1.5$ and 2.5 (ratio between longitudinal pitch and the cylinders diameter). Results showed that the effect of $S_{T} / D$ over drag coefficient and Nusselt number is strongly affected by the magnitude of Richardson number. Concerning the Nusselt number, for $\mathrm{Ri}=$ 0.1 the optimal geometry which maximizes the $\mathrm{Nu}_{\mathrm{D}}$ is reached for the highest magnitude of $\mathrm{S}_{\mathrm{T}} / \mathrm{D}$, while for $\mathrm{Ri}=10.0$ an intermediate optimal ratio of $\mathrm{S}_{\mathrm{T}} / \mathrm{D}$ maximizes the $\mathrm{Nu}_{\mathrm{D}}$. The Richardson magnitudes also have large influence over the fluid dynamic and thermal behavior of fluid flow for all evaluated geometries. An increase in the ratio $S_{L} / D$ improved the heat exchange of the flow, but decreased the fluid dynamic performance.

Keywords: constructal design, arrange of cylinders, geometrical optimization, mixed convection

\section{NOMENCLATURE}

A area, $\mathrm{m}^{2}$

$\mathrm{C}_{\mathrm{D}} \quad$ drag coefficient, $2 F_{\mathrm{d}} /\left(\rho u_{\infty}^{2} A\right)$

D cylinder diameter, $\mathrm{m}$

g gravity acceleration, $\mathrm{m} / \mathrm{s}^{2}$

$\mathrm{Gr}_{\mathrm{D}}$ Grashof number, $g \beta \Delta T D^{3} / v^{2}$

$\mathrm{H}$ height of computational domain, $\mathrm{m}$

$\mathrm{L}$ length of computational domain, $\mathrm{m}$

$\mathrm{L}_{1} \quad$ length from the inlet to the center of the upstream cylinder, $\mathrm{m}$

$\mathrm{Nu}_{\mathrm{D}} \quad$ Nusselt number, $h D / k$

$\mathrm{P}$ pressure, $\mathrm{N} / \mathrm{m}^{2}$

Pr Prandtl number, $v / \alpha$

$\mathrm{Re}_{\mathrm{D}} \quad$ Reynolds number, $\rho u_{\infty} D / \mu$

$\mathrm{Ri} \quad$ Richardson number, $\mathrm{Gr}_{\mathrm{D}} / \mathrm{Re}_{\mathrm{D}}{ }^{2}$

$\mathrm{S}_{\mathrm{L}} \quad$ longitudinal pitch, $\mathrm{m}$

$\mathrm{S}_{\mathrm{T}} \quad$ transversal pitch, $\mathrm{m}$

$\mathrm{T}$ Temperature, $\mathrm{K}$ t Time domain, $\mathrm{s}$

$\mathrm{T}_{\mathrm{w}} \quad$ Cylinder surface temperature, $\mathrm{K}$

$\mathrm{u}_{\infty} \quad$ Free-stram velocity, $\mathrm{m} / \mathrm{s}$

$\mathrm{u}_{\mathrm{w}} \quad$ Wall velocity, $\mathrm{m} / \mathrm{s}$

$\mathrm{v}_{\mathrm{i}} \quad$ Velocity in $i$-direction, $\mathrm{m} / \mathrm{s}$

$x, y, z \quad$ Cartesian coordinates, $\mathrm{m}$

\section{Greek symbols}

$\alpha \quad$ thermal diffusivity, $\mathrm{m}^{2} / \mathrm{s}$

$\beta \quad$ coefficient of thermal expansion, $\mathrm{K}^{-1}$

$\mu \quad$ dynamic viscosity of the fluid, $\mathrm{kg} /(\mathrm{ms})$

$v$ fluid kinematic viscosity, $\mathrm{m}^{2} / \mathrm{s}$

$\rho$ density, $\mathrm{kg} / \mathrm{m}^{3}$

$\Omega \quad$ spatial domain, $\mathrm{m}$

\section{Subscripts}

o once optimized 


\author{
m once maximized \\ w tube surface \\ $\infty \quad$ free stream
}

\section{INTRODUCTION}

Thermal systems involving interactions between fluid flow and surfaces are widely studied and employed to improve the comprehension of various engineering problems. The external flow over cylinders, in particular, ideally represents various engineering problems such as bridges, towers, wind power converters, condensers, evaporators, steam generators, multi-tubular heat exchangers and others. The maximization of heat transfer between the arrangement surfaces and the surrounding flow has also been studied in the literature (Cengel and Cimbala, 2006; Rajani et al.,2009).

Many studies are dedicated to the evaluation of complex phenomenology involved in these flows, such as formation, the detachment of vortex, wake and vortex streets, as well as, the flow patterns as a function of flow parameters (Reynolds, Prandtl and Grashoff numbers). In Sahu et al. (2009) the effect of Reynolds and Prandtl numbers in the fluid dynamic behavior and heat exchange to the surrounding flow were analyzed in a square cylinder and Catalano et al. (2003) evaluated the flow pattern around a circular cylinder for high Reynolds number flows.

In addition to studies about the flow phenomenology, it is also important to understand the geometric influence over the flow behavior and maximization of its fluid dynamic and thermal performance. In this sense, it has been seen an increase on the use of Constructal Design, which is a geometric evaluation method based on constraints and objectives and is based on the physical principle of maximization of internal currents in the flux system. This principle is called Constructal Law and it is defined by (Bejan, 2000) which states that "For a finite size system to persist in time (survive), it needs to evolve its shape and structure to provide better access to current flowing through it". In Bejan and Lorente (2008) many examples of applications of Constructal Law for geometric evaluation of heat transfer problems are presented.

The study of bodies subjected to flow without the use of Constructal Design has also been done in the literature. For example, in Song and Change (1991) are assessed flow patterns and vortex shedding of a laminar flow on a pair of cylinders placed transversally to the main direction of flow, i.e., with side-by-side arrangement (tandem). The behavior of vortices is also studied in Meinders and Hanjalic (1999) for a turbulent flow with forced convection over an array of cubes. Extensive work of literature review is presented in Sumner (2010), in this review work several studies about flows over pair of cylinders with aligned and transverse arrangements are presented. In this study, it was also evaluated the influence of P/D (ratio between the pitch of cylinders and their diameters) on average parameters of the flow as Strouhal number $\left(S_{\text {th }}\right)$, drag coefficients $\left(C_{D}\right)$, support $\left(\mathrm{C}_{\mathrm{L}}\right)$ and number of Nusselt $\left(\mathrm{Nu}_{\mathrm{D}}\right)$. Alam and Zhou (2008) presented a numerical study about fluid flow over two cylinders in tandem with different diameters.

Concerning the geometrical evaluation of heat convection problems by applying Constructal Design, it is possible to mention the work of Bello-Ochende et al. (2007) whose the main purpose was to obtain the minimization of thermal resistance in microchannel cooling. Afterwards, Bello-Ochende et al. (2009) evaluated the effect on heat transfer in ducts using corrugated entries. For the study of flows over cylinders, Bello-Ochende and Bejan (2005) evaluated the heat transfer in a transversal laminar twodimensional flow with natural convection in multiple scales arrangement. Silva and Bejan (2005) presented an evaluation of forced convective flow over arrangements of flat plates with multiple length scales. Later, Kim et al. (2010) carried out a study on forced and natural convection in a cross arrangement of ducts. In this paper it was analyzed the flow of current in the external and internal sides. In BelloOchende et al. (2011) the simulation of flow over arrangements of multiple scales with rotating cylinders was carried out. The results showed that the heat transfer rate increases as the geometric complexity of the structure also increases.

Concerning the multi-objective problem, Rocha et al. (2013) studied numerically forced convective, transients, two-dimensional, incompressible and turbulent (high-Reynolds) flows over a pair of cylinders. In all cases it was considered a flow with $\operatorname{Re}_{\mathrm{D}}=22,000$ and $\operatorname{Pr}=0.71$. The main objective was to evaluate the best angle between the pair of cylinders and the main flow direction that would lead to greater thermal exchange, as well as minimize the drag force between the cylinders and the surrounding flow. As a result, it was demonstrated that the best arrangement taken into account both objectives for the analyzed flow were obtained for angles with the main direction of fluid flow in the range between 45 and 60 degrees. In Galarça et al. (2015) a similar numerical study for a laminar flow with forced convective $\left(\operatorname{Re}_{\mathrm{D}}=100\right.$ and $\left.\mathrm{Pr}=0.71\right)$ flow over a triangular arrangement of cylinders evaluating the influence of longitudinal and transverse steps was performed.

In this work, Constructal Design is applied to optimize the ratio $\mathrm{S}_{\mathrm{T}} / \mathrm{D}$ (ratio between transversal pitch and the cylinders diameter) for two different ratios of $S_{L} / D$ (ratio between longitudinal pitch and the cylinders diameter) in triangular arrangement immersed in flows with mixed, laminar and transient convection with three different numbers of Richardson. More precisely, it is investigated the ratios $S_{L} / D=1.5$ and 2.5. The main goal here is to determine the optimal arrangement that maximizes 
the heat transfer coefficient and minimizes the drag coefficient, for different numbers of Richardson $(\mathrm{Ri}=$ $\mathrm{Gr}_{\mathrm{D}} / \mathrm{Re}_{\mathrm{D}}{ }^{2}=0.1,1.0$ and 10.0), as well as to assess the influence of Richardson number on the optimal geometry and effect of geometry in fluid dynamic and thermal behavior of the flow. Thus, simulated flows are considered dominated by forced convection when $\mathrm{Ri}=0.1$, in balance between forced and mixed convection when $\mathrm{Ri}=1.0$ and dominated by natural convection when $\mathrm{Ri}=10.0$. Note that, Grashoff and Reynolds numbers are given, respectively, by $\mathrm{Gr}_{\mathrm{D}}=$ $g \beta \Delta \mathrm{TD}^{3} / v^{2}$ and $\mathrm{Re}_{\mathrm{D}}=u_{\infty} D / v$. To obtain the velocity fields, pressure and temperature the conservation equations of mass, momentum and energy are solved numerically using the Finite Volume Method (FVM) (Patankar, 1980; Versteeg and Malasekera, 2007; Fluent, 2010).

\section{MATHEMATICAL AND NUMERICAL MODELLING}

The modeling of incompressible flow, transient, with mixed convection in laminar regime is based on the solution of the conservation equations together with the boundary and initial conditions of the problem. The equations of conservation of mass, momentum and energy are given, respectively, by (Bejan, 2004):

$$
\begin{gathered}
\frac{\partial \mathrm{v}_{\mathrm{j}}}{\partial \mathrm{x}_{\mathrm{j}}}=0 \quad(\mathrm{j}=1 \text { and } 2) \text { in } \mathrm{t} \times \Omega \\
\frac{\partial}{\partial \mathrm{t}}\left(\mathrm{v}_{\mathrm{i}}\right)+\frac{\partial}{\partial \mathrm{x}_{\mathrm{j}}}\left(\mathrm{v}_{\mathrm{i}} \mathrm{v}_{\mathrm{j}}\right)+\frac{1}{\rho} \frac{\partial \mathrm{P}}{\partial \mathrm{x}_{\mathrm{j}}} \delta_{\mathrm{ij}}-\frac{\partial}{\partial \mathrm{x}_{\mathrm{j}}}\left\{\mathrm{v}\left(\frac{\partial \mathrm{v}_{\mathrm{i}}}{\partial \mathrm{x}_{\mathrm{j}}}+\frac{\partial \mathrm{v}_{\mathrm{j}}}{\partial \mathrm{x}_{\mathrm{i}}}\right)\right\} \\
+\rho \mathrm{g}_{\mathrm{i}} \beta\left(\mathrm{T}-\mathrm{T}_{0}\right)=0 \\
\frac{\partial \mathrm{T}}{\partial \mathrm{t}}+\frac{\partial}{\partial \mathrm{x}_{\mathrm{j}}}\left(\mathrm{v}_{\mathrm{j}} \mathrm{T}\right)-\frac{\partial}{\partial \mathrm{x}_{\mathrm{j}}}\left\{\alpha \frac{\partial \mathrm{T}}{\partial \mathrm{x}_{\mathrm{j}}}\right\}-\mathrm{q}^{\prime \prime \prime}=0 \\
(\mathrm{j}=1 \text { and } 2) \text { in } \mathrm{t} \times \Omega
\end{gathered}
$$

where $\rho$ is the density of the fluid $\left(\mathrm{kg} / \mathrm{m}^{3}\right) ; \mu$ is the dynamic viscosity of the fluid $(\mathrm{kg} /(\mathrm{ms}))$; $v$ is the kinematic viscosity of the fluid $\left(\mathrm{m}^{2} / \mathrm{s}\right) ; \alpha$ is the thermal diffusivity $\left(\mathrm{m}^{2} / \mathrm{s}\right) ; \mathrm{v}_{\mathrm{i}}$ is the fluid velocity in direction $\mathrm{i}, \mathrm{i}=1$ and $2(\mathrm{~m} / \mathrm{s}) ; \mathrm{x}_{\mathrm{i}}$ represents the spatial coordinate in the direction $i, i=1$ and $2(\mathrm{~m}) ; \mathrm{P}$ is the pressure $\left(\mathrm{N} / \mathrm{m}^{2}\right)$; $\mathrm{T}$ is the temperature $\left({ }^{\circ} \mathrm{C} \mathrm{ou} \mathrm{K}\right) ; \delta_{\mathrm{ij}}$ is the operator Kronecker delta; $\mathrm{g}_{\mathrm{i}}$ is the acceleration of gravity in the direction $i ; \beta$ is the coefficient of thermal expansion $\left(\mathrm{K}^{-1}\right)$; is the spatial domain $(\mathrm{m})$; $\mathrm{t}$ is the time domain (s), and $\mathrm{q}^{\prime \prime \prime}$ is the term source of energy, which for the simulated cases in this study is null.

The Equations (1) - (3) are resolved through a commercial software of Computational Fluid Dynamics (CFD) that is based on the Finite Volume
Method (FVM) (Patankar, 1980; Versteeg and Malasekera, 2007). In all simulations rectangular finite volume were used. The solver is based on pressure, the pressure-velocity coupling was performed using SIMPLE algorithm and for the treatment of advective terms it is used the Upwind interpolation scheme of second order for momentum and energy conservation equations. Additionally, calculations were considered converged when the residuals for the mass, momentum and energy conservation equations between two consecutive iterations are smaller than $10^{-6}, 10^{-6}$ e $10^{-8}$, respectively. Further details related to the FVM can be found in Patankar (1980) and Versteeg and Malasekera (2007).

The numerical simulations were performed using a computer with two Intel dual-core processor with $3.6 \mathrm{GHz}$ clock and $24 \mathrm{~GB}$ of RAM. For parallelization was used the message passing library (Message Passing Interface). The processing time for each simulation was approximately $7.20 \times 10^{2} \mathrm{~s}$. The grid independence study followed the same procedure presented in previous work of Galarça et al. (2015). The results were grid independent for a domain discretized with nearly 63,000 rectangular finite volumes.

\section{PROBLEM DESCRIPTION}

It is considered a flow over a triangular arrangement of cylinders with the same diameter $\mathrm{D}=$ $0.1 \mathrm{~m}$. The computational domain has the following dimensions: $\mathrm{L}=35.0 \mathrm{D}=3.5 \mathrm{~m}, \mathrm{H}=15.0 \mathrm{D}=1.5 \mathrm{~m}$, $\mathrm{L}_{1}=8 \mathrm{D}=0.8 \mathrm{~m}$. Figure 1 shows the flow domain with the degrees of freedom evaluated in the present study: $S_{T} / D$ and $S_{L} / D$. Regarding the fluid dynamic behavior of the flow, it is generated by imposing a constant velocity profile $\mathrm{u}_{\infty}$ at the entrance surface and also the buoyancy force arising from the temperature difference between the cylinder and the surrounding flow. The problem is solved by similarity to ensure $\operatorname{Re}_{\mathrm{D}}$ and $\mathrm{Gr}_{\mathrm{D}}$. The surfaces of the cylinders have the condition of non-slip boundary and impermeability $\left(u_{\mathrm{w}}=0 \mathrm{~m} / \mathrm{s}\right)$. The upper and lower surfaces have a symmetry condition and the right side surface has a zero gauge pressure boundary condition. The natural convection is caused by the action of the gravitational field, which in this work is considered by a field force (Boussinesq hypothesis). The acceleration of the gravitational field is also illustrated in Fig. 1. For the thermal problem, the heating fluid is caused by the temperature difference between the free stream flow $\left(\mathrm{T}_{\infty}=20^{\circ} \mathrm{C}\right)$ and the imposed temperature surfaces at the cylinders surfaces $\left(\mathrm{T}_{\mathrm{w}}=30^{\circ} \mathrm{C}\right)$.

For the geometric optimization problem is employed the method Constructal Design (Bejan, 2000) and (Bejan and Lorente, 2008). Constructal Design is a method based on the objectives and constraints principle (local and global) and the 
method used to apply the Constructal Law, as previously mentioned. For the problem analyzed were defined as geometric constraints of the problem: the area occupied by the three cylinders, which is the same in all cases $\left(A_{t}=A_{c 1}+A_{c 2}+A_{c 3}\right)$ the diameters of the cylinders are equal $\left(D_{1}=D_{2}=D_{3}=D\right)$ and the space occupied by the pair of cylinders further to the first cylinder can not exceed the height of the employed computational domain $\left(\mathrm{S}_{\mathrm{T}}+\mathrm{D}<\mathrm{H}\right)$.

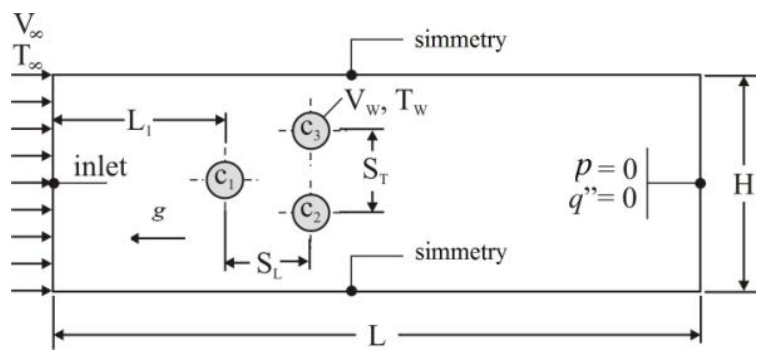

Figure 1. Computational domain of laminar flow on a triangular arrangement of cylinders with $\operatorname{Re}_{\mathrm{D}}=$ 100 and $\operatorname{Pr}=0.71$.

The optimization procedure is divided into two steps, as shown in Fig. 2. In the first step, the geometry is optimized by varying the degree of freedom $\mathrm{S}_{\mathrm{T}} / \mathrm{D}$ keeping constant the $\mathrm{S}_{\mathrm{L}} / \mathrm{D}$ parameter. The geometry that lead to the highest value of the Nusselt number $\left(\mathrm{Nu}_{\mathrm{D}}\right)$ will be optimum for the thermal problem and the one that lead to the lowest value for the coefficient of drag $\left(C_{D}\right)$ is the optimum geometry for fluid dynamic problem. The corresponding $\mathrm{S}_{\mathrm{T}} / \mathrm{D}$ parameter is once optimized, $\left(\mathrm{S}_{\mathrm{T}} / \mathrm{D}\right)_{\mathrm{o}}$. In the second step, the same process is repeated for several $S_{L} / D$ values. In the present study, the $S_{L} / D$ parameter is kept fixed $\left(S_{L} / D=1.5\right.$ and 2.5$)$, while the $\mathrm{S}_{\mathrm{T}} / \mathrm{D}$ parameter is varied in the following range $\left(1.5 \leq \mathrm{S}_{\mathrm{T}} / \mathrm{D} \leq 5.0\right)$. This process is repeated for each studied Richardson number, in this case three values: $\mathrm{Ri}=\mathrm{Gr}_{\mathrm{D}} / \mathrm{Re}_{\mathrm{D}}^{2}=0.1,1.0$ e 10.0 .

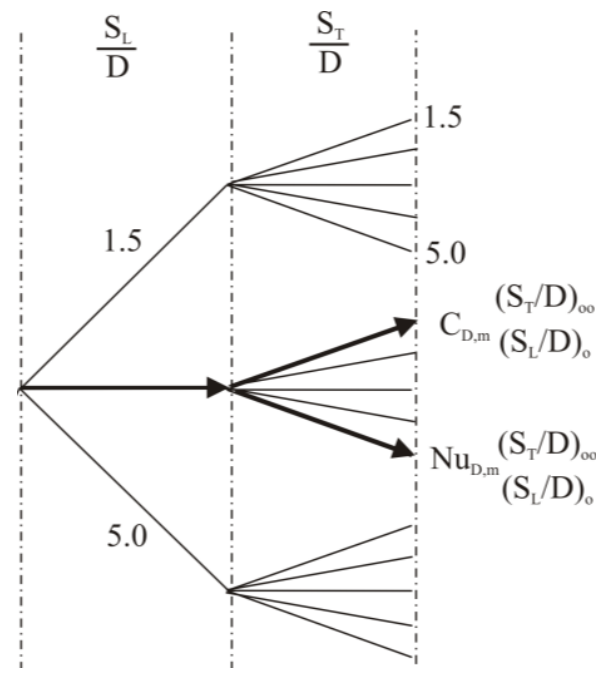

Figure 2. Diagram illustrating the optimization process to a problem with two degrees of freedom.

\section{RESULTS AND DISCUSSION}

Figure 3 shows the effect of the ratio $S_{\mathrm{T}} / D$ on the drag coefficient $\left(C_{D}\right)$ for $S_{L} / D=1.5$ (Fig. 3(a)) and $\mathrm{S}_{\mathrm{L}} / \mathrm{D}=2.5$ (Fig. 3(b)) with $\mathrm{Ri}=0.1$ (flow dominated by forced convection). In general, it can be seen that the drag coefficient increases as the transverse pitch also increases for all the cylinders. However, for the upstream cylinder $\left(\mathrm{C}_{1}\right)$, the variation magnitude with $\mathrm{S}_{\mathrm{T}} / \mathrm{D}$ is more significant $\left(\mathrm{C}_{\mathrm{D}}=1.0\right.$ in $\mathrm{S}_{\mathrm{T}} / \mathrm{D}=1.5$ to $\mathrm{C}_{\mathrm{D}} \cong 1.8$ in $\left.\mathrm{S}_{\mathrm{T}} / \mathrm{D}=5.0\right)$ than for the downstream cylinders $\left(\mathrm{C}_{2}\right.$ and $\left.\mathrm{C}_{3}\right)$. This behavior is mainly related to the pressure difference between the front and rear region of the first cylinder. For the case $S_{T} / D=1.5$ where the cylinders are very close and there is no formation of a low-pressure in a region posterior to the upstream cylinder $\mathrm{C}_{1}$. Moreover, cylinders $\mathrm{C}_{2}$ and $\mathrm{C}_{3}$ also benefit themselves in the fluid dynamic framework of this flow condition. As the ratio $\mathrm{S}_{\mathrm{T}} / \mathrm{D}$ increases cylinders tend to face almost individually the free stream flow imposed, leading to an increase of drag coefficient in the arrangement of cylinders. This also explains the fact that in the case of the ratio $S_{L} / D=2.5$. When the horizontal distance between the first cylinder and the subsequent ones is higher, they have been a minor variation in $C_{D}$, especially for $C_{1}$. Furthermore, for the highest evaluated ratio of $S_{L} / D$ the drag coefficient for three cylinders converges to the same values when the three cylinders have the highest separation.

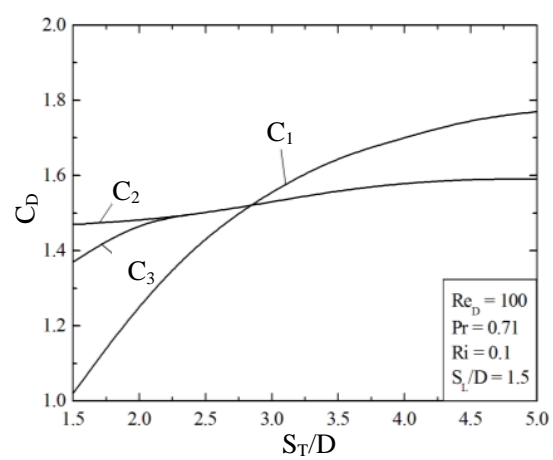

a)

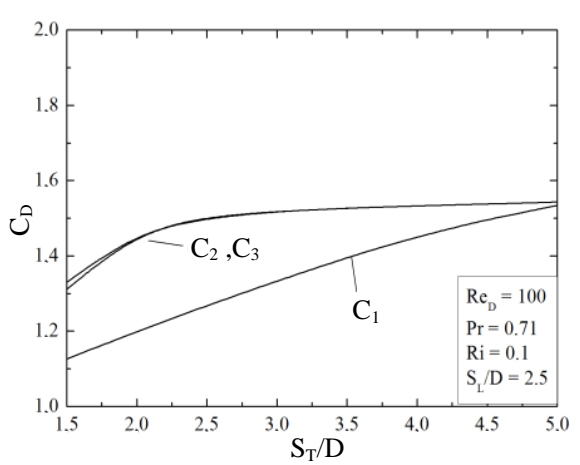

b)

Figure 3. Effect of parameter $S_{T} / D$ over $C_{D}$ in each cylinder for a flow with $\operatorname{Re}_{\mathrm{D}}=100, \operatorname{Pr}=0.71$ and $\mathrm{Ri}=0.1:$ a) $\mathrm{S}_{\mathrm{L}} / \mathrm{D}=1.5$, b) $\mathrm{S}_{\mathrm{L}} / \mathrm{D}=2.5$. 
Regarding the Nusselt number $\left(\mathrm{Nu}_{\mathrm{D}}\right)$, it is possible to see in Fig. 4 a similar behavior to that obtained for the drag coefficient $\left(C_{D}\right)$ in the three cylinders. Figure 4(a) shows the $\mathrm{Nu}_{D}$ as function of $\mathrm{S}_{\mathrm{T}} / \mathrm{D}$ for $\mathrm{S}_{\mathrm{L}} / \mathrm{D}=1.5$ and Fig. 4(b) for an arrangement with $S_{L} / D=2.5$. For the cylinder $C_{1}$, there is a small $\mathrm{Nu}_{\mathrm{D}}$ for the smaller ratios $\mathrm{S}_{\mathrm{T}} / \mathrm{D}$, and as the spacing between the cylinders increase there is also an increase in the $\left(\mathrm{Nu}_{\mathrm{D}}\right)$ of this cylinder. The smaller values of $\left(\mathrm{Nu}_{\mathrm{D}}\right)$ in the lowest regions of $\mathrm{S}_{\mathrm{T}} / \mathrm{D}$ are caused by the fact that subsequent cylinders are placed behind cylinder $\mathrm{C}_{1}$, forming a single boundary layer composed of three cylinders that difficult heat transfer. It can also be noticed that there is a convergence of the Nusselt number for the cylinder to more distant ratios $S_{T} / D$. This behavior is related to the lack of interaction between the thermal boundary layers for these cases. This behavior is very similar for the cases with $S_{L} / D=1.5$ and 2.5 with a slight difference between the cases, where it can be seen a less pronounced change in value of $C_{1}$ for $S_{L} / D=1.5$.

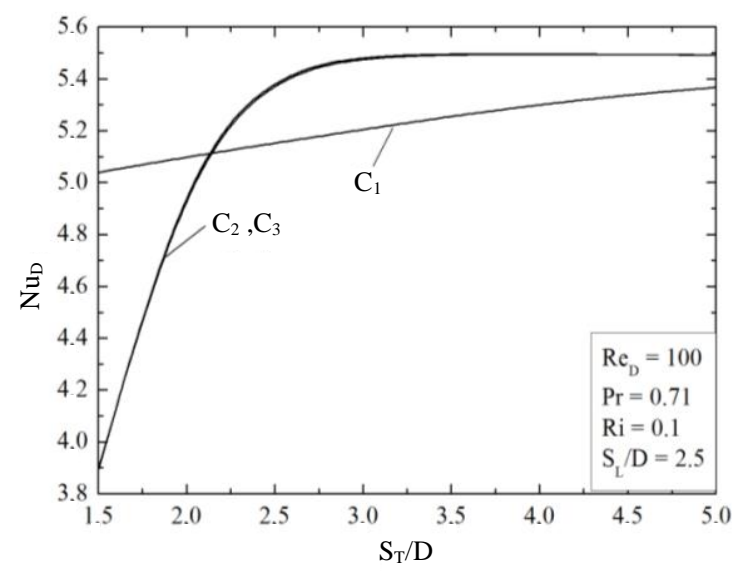

a)

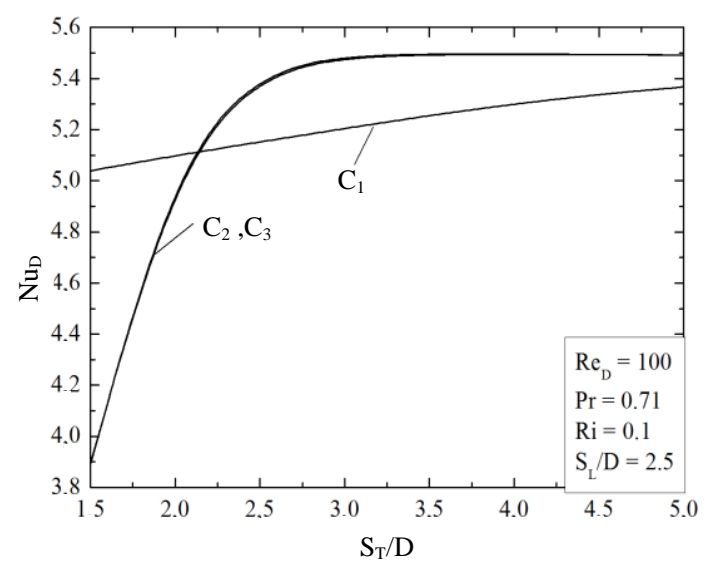

b)

Figure 4. Effect the parameter $\mathrm{S}_{\mathrm{T}} / \mathrm{D}$ over $\mathrm{Nu}_{\mathrm{D}}$ in each cylinder for a flow with $\operatorname{Re}_{\mathrm{D}}=100, \operatorname{Pr}=0.71$ and $\mathrm{Ri}=0.1$ : a) $\mathrm{S}_{\mathrm{L}} / \mathrm{D}=1.5$, b) $\mathrm{S}_{\mathrm{L}} / \mathrm{D}=2.5$.

Figure 5 shows the effect of the ratio $\mathrm{S}_{\mathrm{T}} / \mathrm{D}$ on the drag coefficient $\left(\mathrm{C}_{\mathrm{D}}\right)$ for $\mathrm{Ri}=10.0$ (dominant natural convection) where $S_{L} / D=1.5$ and 2.5 , Fig. 5(a) and 5(b), respectively. In general, the magnitudes of the drag coefficients for all the cylinders $\left(\mathrm{C}_{1}, \mathrm{C}_{2}\right.$ and $\left.\mathrm{C}_{3}\right)$ increased compared to the case $\mathrm{Ri}=0.1$, which was expected since in the present simulations it has been performed a combination of the forced convective with natural convective. In this sense, the flow intensity increases with increasing the number of Grashoff.

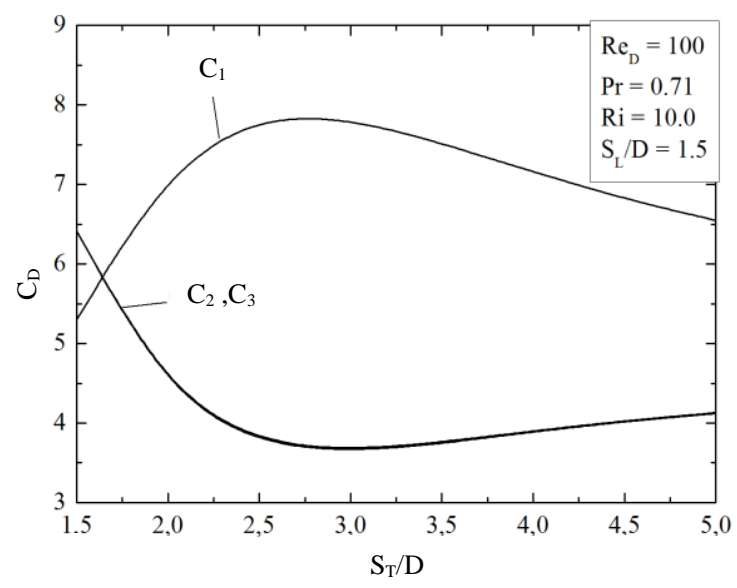

a)

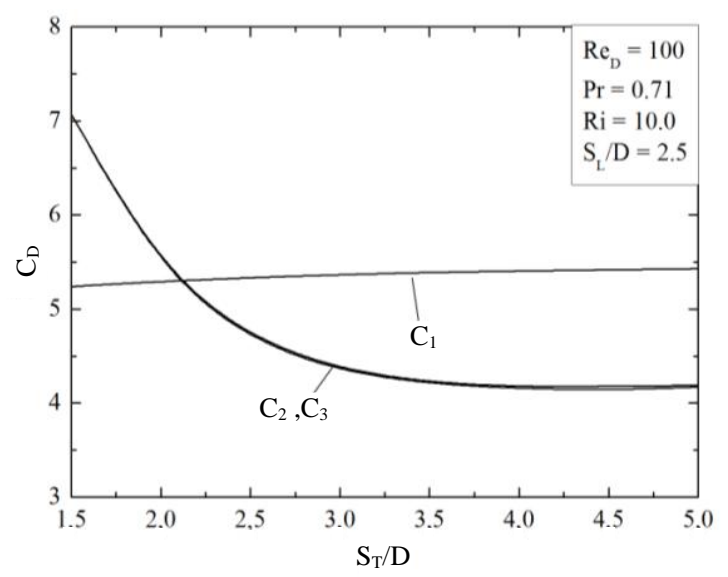

b)

Figure 5. Effect of parameter $\mathrm{S}_{\mathrm{T}} / \mathrm{D}$ on $\mathrm{C}_{\mathrm{D}}$ for each cylinder for a flow with $\operatorname{Re}_{\mathrm{D}}=100, \operatorname{Pr}=0.71$ and

$$
\mathrm{Ri}=10.0 \text { : a) } \mathrm{S}_{\mathrm{L}} / \mathrm{D}=1.5 \text {, b) } \mathrm{S}_{\mathrm{L}} / \mathrm{D}=2.5 \text {. }
$$

Figure 5 also illustrates that the effect of $\mathrm{S}_{\mathrm{T}} / \mathrm{D}$ is different from those for the cases previously presented in Galarça et al. (2015) for forced convective flows and that ones achieved here for $\mathrm{Ri}=$ 0.1 . The drag coefficient $C_{D}$ for the cylinder $C_{1}$ increases its magnitude with the increase of the ratio $\mathrm{S}_{\mathrm{T}} / \mathrm{D}$ up to a maximum $\mathrm{S}_{\mathrm{T}} / \mathrm{D}=2.5$. After this point there is a decrease in the magnitude $\mathrm{C}_{\mathrm{D}}$, which does not occur in case with $\mathrm{Ri}=0.1$. For $\mathrm{C}_{2}$ and $\mathrm{C}_{3}$ cylinders behavior is even more different from that for $\mathrm{Ri}=0.1$. For smaller ratios of $\mathrm{S}_{\mathrm{T}} / \mathrm{D}$ the $\mathrm{C}_{\mathrm{D}}$ decreases to a minimum point in $\mathrm{S}_{\mathrm{T}} / \mathrm{D}=3.0$. Subsequently, the magnitude of $C_{D}$ grows up again. One possible explanation for this behavior is the fact that for $\mathrm{Ri}=10.0$ the main flow is driven dominantly 
by natural convection. For this case, the plume generated in the upstream cylinder intensifies the momentum in cylinders $\mathrm{C}_{2}$ and $\mathrm{C}_{3}$ up to an intermediate ratio of $\mathrm{S}_{\mathrm{T}} / \mathrm{D}$ where the thickness of fluid dynamic boundary layer generated behing cylinder $\mathrm{C}_{1}$ has a lower influence over the downstream cylinders.

Figure 6 shows the effect of the ratio $S_{T} / D$ for a flow with $\mathrm{Re}_{\mathrm{D}}=100, \mathrm{Pr}=0.71$ and $\mathrm{Ri}=10.0$ for two different ratios of $S_{L} / D=1.5$ and 2.5, Figs. 6(a) and (b), respectively. Concerning the Nusselt number $\left(\mathrm{Nu}_{\mathrm{D}}\right)$, as expected, the association with natural convection for flows with higher number of Grashoff leads to a more intense heat transfer rate in all the cylinders. It is also observed that the $\mathrm{S}_{\mathrm{T}} / \mathrm{D}$ effect is quite different from the one observed in forced convective case (Galarça et al., 2015). In this case it is observed optimal intermediate ratios for each cylinder, which was not obtained in cases where forced convection is dominant. In this case $(\mathrm{Ri}=$ 10.0 ), for the lowest ratios $S_{T} / D$, there is interference between the thermal boundary layers of each cylinder, hindering the heat exchange between the cylinders and the flow. At the highest extreme of $\mathrm{S}_{\mathrm{T}} / \mathrm{D}$, the thermal performance is also minimized due to the decrease of momentum among cylinders.

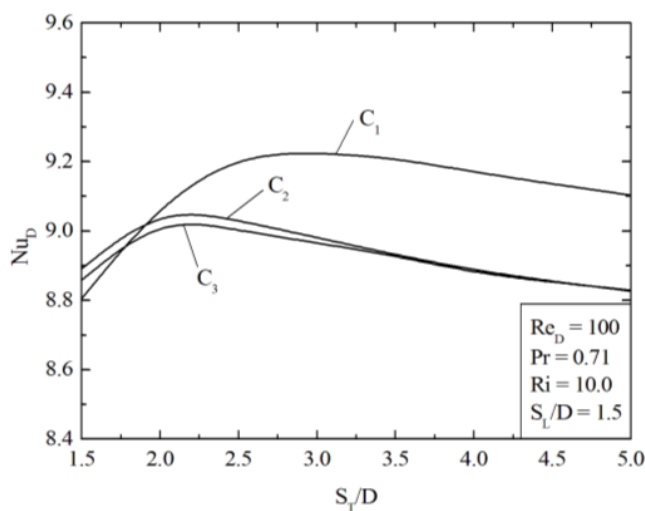

a)

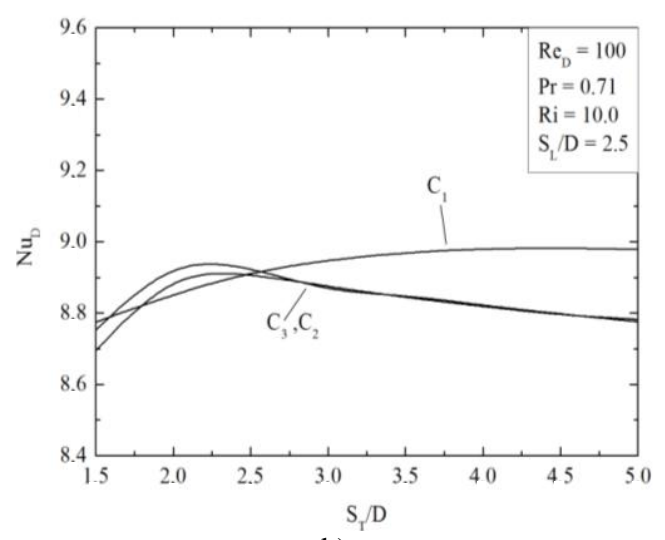

b)

Figure 6. Effect of parameter $\mathrm{S}_{\mathrm{T}} / \mathrm{D}$ on $\mathrm{Nu}_{\mathrm{D}}$ for each cylinder for a flow with $\operatorname{Re}_{\mathrm{D}}=100, \mathrm{Pr}=0.71$ and

$$
\mathrm{Ri}=10.0 \text { : a) } \mathrm{S}_{\mathrm{L}} / \mathrm{D}=1.5 \text {, b) } \mathrm{S}_{\mathrm{L}} / \mathrm{D}=2.5 \text {. }
$$

Once again the flow has presented a very similar behavior in the two cases $S_{L} / D$, with exception of the cylinder $C_{1}$ where for $S_{L} / D=1.5$ the highest $\mathrm{Nu}_{\mathrm{D}}$ is obtained for $\left(\mathrm{S}_{\mathrm{T}} / \mathrm{D}\right)_{\mathrm{o}}=2.75$ while for $\mathrm{S}_{\mathrm{L}} / \mathrm{D}=2.5$ this optimal point was displaced for $\left(\mathrm{S}_{\mathrm{T}} / \mathrm{D}\right)_{\mathrm{o}}=4.5$. It is still possible to observe that the variation of the longitudinal pitch has lower influence over the Nusselt number $\left(\mathrm{Nu}_{\mathrm{D}}\right)$ than that noticed for the drag coefficient $\left(\mathrm{C}_{\mathrm{D}}\right)$.

Figure 7 shows the average for the arrangement of cylinders (mean between the three evaluated cylinders) of drag coefficient $\left(\mathrm{C}_{\mathrm{D}}\right)$ (Fig. 7(a)) and Nusselt number $\left(\mathrm{Nu}_{\mathrm{D}}\right)$ (Fig. $7(\mathrm{~b})$ ) for two different ratios of $S_{\mathrm{L}} / D$ evaluated. In general, it can be noticed that the change in the longitudinal distance between upstream and downstream cylinders for the evaluated values does not lead to large differences in both $C_{D}$ and $\mathrm{Nu}_{\mathrm{D}}$. Results allowed the observation that different Richardson numbers led to differences in the effect of the ratio $S_{\mathrm{T}} / D$ over $\mathrm{C}_{\mathrm{D}}$ and $\mathrm{Nu}_{\mathrm{D}}$ for the arrangement of cylinder. In this sense, results proved the influence of flow intensity and dimensionless parameters not only over the magnitudes of $C_{D}$ and $\mathrm{Nu}_{\mathrm{D}}$ but also over the effect of geometry over $\mathrm{C}_{\mathrm{D}}$ and $\mathrm{Nu}_{D}$. It is also noticed that there is no universal configuration which leads to the best fluid dynamic and thermal performance, i.e., the design must be evaluated for each problem individually.

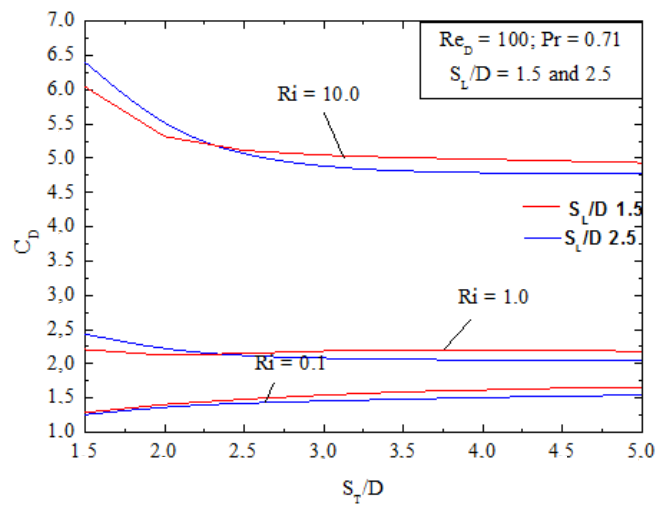

a)

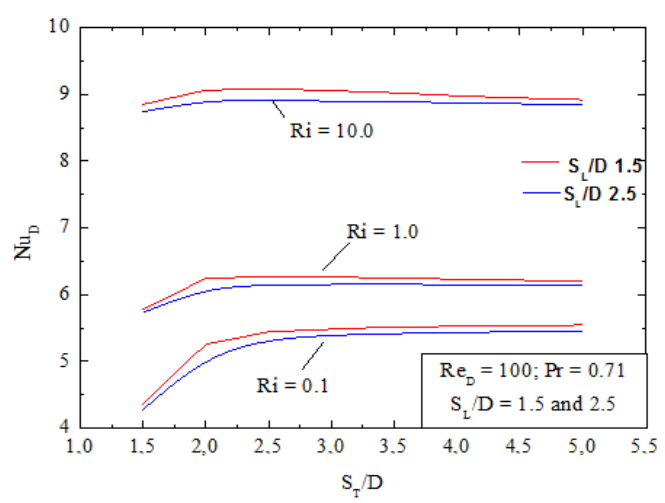

b)

Figure 7. Effect of Richardson number (Ri) for a flow with $\operatorname{Re}_{\mathrm{D}}=100, \operatorname{Pr}=0.71$ over: a) $C_{\mathrm{D}}$, b) $\mathrm{Nu}_{\mathrm{D}}$. 


\section{CONCLUSIONS}

A numerical study was conducted to evaluate the geometric shape of a triangular arrangement of cylinders subjected to laminar flows with mixed convection employing Constructal Design. The simulations were performed for Reynolds numbers and Prandtl of $\operatorname{Re}_{\mathrm{D}}=100$ and $\operatorname{Pr}=0.71$ evaluating the problem geometry for three different Richardson numbers $\mathrm{Ri}=0.1,1.0$ and 10.0. The momentum and energy conservation equations were solved using the finite volume method (FVM). The main objective was to evaluate the influence of $\mathrm{Ri}$ in the effect of the ratio $\mathrm{S}_{\mathrm{T}} / \mathrm{D}$ (ratio between transversal pitch and the cylinder diameter) over the drag coefficient $\left(C_{D}\right)$ and the Nusselt number $\left(\mathrm{Nu}_{\mathrm{D}}\right)$ for two different magnitudes of $S_{L} / D=1.5$ and 2.5.

Results showed that increasing the number of Richardson led to growth of the magnitudes of the drag coefficient $\left(\mathrm{C}_{\mathrm{D}}\right)$ and Nusselt number $\left(\mathrm{Nu}_{\mathrm{D}}\right)$. In addition, there was a significant change in the effect of the ratio $S_{T} / D$ over $C_{D}$ and $\mathrm{Nu}_{\mathrm{D}}$. For forced convective dominant cases $(\mathrm{Ri}=0.1)$ the optimal geometry into the thermal framework is achieved for the highest ratio of $S_{T} / D$, i.e., when the cylinders are the most distant possible. On the opposite, for natural convection dominated flows $(\mathrm{Ri}=10.0)$ intermediate ratios of $\mathrm{S}_{\mathrm{T}} / \mathrm{D}$ led to the best results. It was also noticed the non-occurrence of an universal configuration which led to the best fluid dynamic and thermal performance. In this sense, the design of the arrangement of cylinders must be evaluated individually according to dimensionless parameters that ruled the fluid flow with convection heat transfer.

\section{ACKNOWLEDGEMENTS}

The authors G. M. Barros and M. dos S. Pereira thanks CAPES by scholarship. The authors L. A. Isoldi, L. A. O. Rocha and E. D. dos Santos thanks $\mathrm{CNPq}$ for research grant. All authors thank CNPq for financial support.

\section{REFERENCES}

Alam, M. M., and Zhou, Y., 2008, Strouhal Numbers, Forces and Flow Structures Around Two Tandem Cylinders of Different Diameters, Journal of Fluid Structures, Vol. 24, pp. 505-526.

Bejan, A., 2004, Convection Heat Transfer, John Wiley.

Bejan, A., and Lorente, S., 2008, Design with Constructal Theory, Wiley.

Bejan, A., 2000, Shape and Structure, from Engineering to Nature, Cambridge University Press, Cambridge, UK.

Bello-Ochende, T., and Bejan, A., 2005, Constructal Multi-Scale Cylinders with Natural Convection, International Journal of Heat and Mass
Transfer, Vol. 48, pp. 4300-4306.

Bello-Ochende, T., Lienbenberg, L., Malan, A. G., Bejan, A., and Meyer, J. P., 2007, Constructal Conjugate Heat Transfer in Three-Dimensional Cooling Channels, Journal of Enhancement Heat Transfer, Vol. 14, pp. 279-293.

Bello-Ochende, T., Lienbenberg, L., Malan, A. G., Bejan, A., and Meyer, J. P., 2009, Constructal Ducts with Wrinkled Entrances, International Journal of Heat and Mass Transfer, Vol. 52, pp. 3628-3633.

Bello-Ochende, T., Meyer, J. P., and Ogunronbi, O. I., 2011, Constructal Multiscale Cylinders Rotating in Cross-Flow, International Journal of Heat and Mass Transfer, Vol. 54, pp. 2568-2577.

Catalano, P., Wang, M., Iaccarino, G., and Moin, P., 2003, Numerical Simulation of the Flow around a Circular Cylinder at High Reynolds Numbers, International Journal of Heat and Fluid Flow, Vol. 24, pp. 463-469.

Çengel, Y. A., and Cimbala, J. M., 2006, Fluid Mechanics: Fundamentals and Application, McGraw-Hill.

Fluent (version 13.0), 2010, ANSYS, Inc.

Galarça, M. M., Cardoso, F. R., Razera, A. L., Acunha Jr., I. C., Isoldi, L. A., Porte, A. F., Rocha, L. A. O., and Dos Santos, E. D., 2015, Geometrical Optimization of an Triangular Arrangement of Cylinders Submitted to Laminar Forced Convective Flow, Scientia Plena, Vol. 11, No. 5, pp. 021706-1021706-13.

Kim, Y., Lorente, S., and Bejan, A., 2010, Constructal Multi-Tube Configuration for Natural and Forced Convection in Cross-Flow, International Journal of Heat and Mass Transfer, Vol. 53, pp. 5121-5128.

Meinders, E. R., and Hanjalic, K.,1999, Vortex Structure and Heat Transfer in Turbulent Flow Over a Wall-Mounted Matrix of Cubes, International Journal of Heat and Fluid Flow, Vol. 20, pp. 255-267.

Patankar S. V., 1980, Numerical Heat Transfer and Fluid Flow, McGraw Hill.

Rajani, B. N., Kandasamy, A., and Majumdar, S., 2009, Numerical Simulation of Laminar Flow Past a Circular Cylinder, Applied Mathematical Modeling, Vol. 33, pp. 1228-1247.

Rocha, L. A. O., Gomes, M. N., Porte, A. F., Galarça, M. M., Acunha Jr, I. C., Da Silva, F. M. V., Isoldi, L. A., and Dos Santos, E. D., 2013, Constructal Design of Turbulent Forced Convective Flows Over a Pair of Circular Cylinders, in: Constructal Law Conference, Nanjing, Proceedings of Constructal Law Conference, pp. 174-184.

Sahu, A. K., Chhabra R. P., and Eswaran, V., 2009, Effects of Reynolds and Pradtl Numbers on Heat Transfer from a Square Cylinder in the Unsteady Flow Regime, International Journal of Heat and Mass Transfer, Vol. 52, pp. 839-850.

Silva, A. K., and Bejan, A., 2005, Constructal Multi-Scale Structure for Maximal Heat Transfer 
Density in Natural Convection, International Journal of Heat and Fluid Flow, Vol. 26, pp. 34-44.

Song, C. -J., and Chang, K. -S., 1991, Heat Transfer and Interactive Buoyant Vortex Sheeding by a Pair of Circular Cylinders in Transverse Arrangement, International Journal of Heat and Mass Transfer, Vol. 34, pp. 1347-1354.

Summer, D., 2010, Two Circular Cylinders in Cross-Flow: a Review, Journal of Fluid Structure, Vol. 26, pp. 849-899.

Versteeg, H. K., and Malalasekera, W., 2007, An Introduction to Computational Fluid Dynamics The Finite Volume Method, Pearson. 